\title{
Fine-Needle Aspiration of Subcentimeter Thyroid Nodules in the Real-World Management
}

This article was published in the following Dove Press journal:

Cancer Management and Research

\author{
Chaiho Jeong (D) \\ Hyunsam Kim' \\ Jeongmin Lee $\mathbb{D}^{2}$ \\ Jeonghoon $\mathrm{Ha} \mathbb{D}^{1}$ \\ Min-Hee $\mathrm{Kim}^{2}$ \\ Moo II Kang' \\ Dong-Jun Lim (D) \\ 'Division of Endocrinology and \\ Metabolism, Department of Internal \\ Medicine, Seoul St. Mary's Hospital, \\ College of Medicine, The Catholic \\ University of Korea, Seoul, Republic of \\ Korea; ${ }^{2}$ Division of Endocrinology and \\ Metabolism, Department of Internal \\ Medicine, Eunpyeong St. Mary's Hospital, \\ College of Medicine, The Catholic \\ University of Korea, Seoul, Republic of \\ Korea
}

Correspondence: Dong-Jun Lim Division of Endocrinology and Metabolism, Department of Internal Medicine, Seoul St. Mary's Hospital, College of Medicine, The Catholic University of Korea, 222, Banpo-Daero, Seocho-Gu, Seoul 0659I, Republic of Korea

Tel +82-2-2258-6009

Fax $+82-2-599-3589$

Email Idj6026@catholic.ac.kr
Background: The Korea Thyroid Association published the revised guidelines for thyroid nodules in 2016. However, whether fine-needle aspiration is accurately performed based on indications and whether the results of this procedure are appropriately addressed according to clinical guidelines, particularly in subcentimeter nodules, are unclear.

Methods: We retrospectively analyzed the fine-needle aspiration data of 331 thyroid nodules of patients who were referred to a tertiary hospital clinic for fine-needle aspiration. Each nodule was categorized according to ultrasonography findings based on the recommendations of the Korea Thyroid Association for fine-needle aspiration. Only nodules with a final pathological diagnosis of benign or malignant made using the Bethesda system were included.

Results: Up to $32 \%$ of thyroid nodules that were not indicated for fine-needle aspiration were aspirated. Regarding subcentimeter nodules, only 28 of 123 (22.8\%) aspirated nodules were indicated for fine-needle aspiration. Of the 49 malignant subcentimeter nodules, 33 (67.3\%) underwent immediate surgery. Meanwhile, 14 (28.6\%) nodules were lost to followup, and two (4.1\%) were under active surveillance. Eighteen $(36.7 \%)$ malignant subcentimeter nodules were not indicated for fine-needle aspiration but underwent surgical resection instead of active surveillance.

Conclusion: Despite the recommendations in the revised guidelines, several thyroid nodules that do not meet the indications for FNA are aspirated in real-world practice. To reduce overtreatment, a widespread knowledge of the correct indications for fine-needle aspiration is important in clinical practice, particularly for subcentimeter nodules.

Keywords: thyroid nodule, fine-needle aspiration, thyroid cancer, KTA guidelines

\section{Introduction}

Thyroid nodules are extremely common, and their incidence has been increasing over the last several decades in several countries, ${ }^{1-4}$ including South Korea. ${ }^{5}$ In Korea, health screening with thyroid ultrasonography (US) is frequently performed in the general population. The easy access to thyroid US led to the rapid detection of thyroid nodules, which resulted in an up to 15 -fold increase in cancer diagnosis. ${ }^{6}$ However, the mortality rate of thyroid cancer has not decreased, ${ }^{5}$ indicating that overdiagnosis unrelated to mortality is prevalent. Recent issues with the overdiagnosis of thyroid cancer have raised the need for more thorough guidelines for the indication of thyroid biopsy. ${ }^{7}$

The Korean Thyroid Association (KTA) published the revised guidelines for thyroid nodules and cancer in 2016. The indications for fine-needle aspiration (FNA) of thyroid nodules based on the Korean Thyroid Imaging Reporting and 
Data System (K-TIRADS) are clearly presented. ${ }^{8}$ In an era of explosive detection of thyroid nodules and repeated revision of clinical guidelines, whether FNA is accurately performed based on indications in real-world practice is unclear. Furthermore, there is still no consensus about the indications for FNA in suspicious subcentimeter nodules, and the decision varies between physicians. The present study aimed to assess whether FNA is accurately performed in real-world practice and to provide FNA data of subcentimeter nodules for future guidelines.

\section{Patients and Methods}

\section{Study Population and Cytological Examination}

We retrospectively analyzed the data of 395 patients with 465 nodules who were referred to a tertiary hospital clinic for thyroid nodule biopsy by primary physicians from January 2017 to April 2018. Based on the US findings of the nodules, the patients either underwent further cytological examination via FNA in a tertiary hospital clinic or were transferred back to their primary clinics for continuous surveillance for thyroid nodules without biopsy. A total of $90(19.4 \%)$ patients who were transferred back to the primary clinics without FNA were excluded from our study (Figure 1). Seventy-six nodules did not meet the criteria for conducting an FNA according to the guidelines, eight patients were found to have benign nodules prior to FNA, and six patients refused to undergo FNA.

Finally, 375 nodules underwent further cytological examination. The FNA cytology results were evaluated using the Bethesda System for Reporting Thyroid Cytopathology. ${ }^{9,10}$ Since the Bethesda System recommends repeat biopsy for Bethesda categories I and III nodules and diagnostic surgery for category IV nodules, patients with category I, III, and IV nodules who did not have a definite diagnosis after repeat biopsy or refused further evaluation were excluded. Data of nodules were excluded after FNA for the following: Bethesda category I nodules, $\mathrm{n}=28$; Bethesda category III nodules, $\mathrm{n}=9$; and Bethesda category IV nodules, $n=7$. Finally, data of 331 nodules were included in the analysis. Bethesda category II nodules were considered benign without further work-up. In terms of final outcome, Bethesda category $\mathrm{V}$ nodules (suspicious for malignancy), Bethesda VI nodules (malignant), or nodules found to be malignant based on surgical pathology were classified as malignant. The study adhered to the tenets of the Declaration of Helsinki and was approved by the

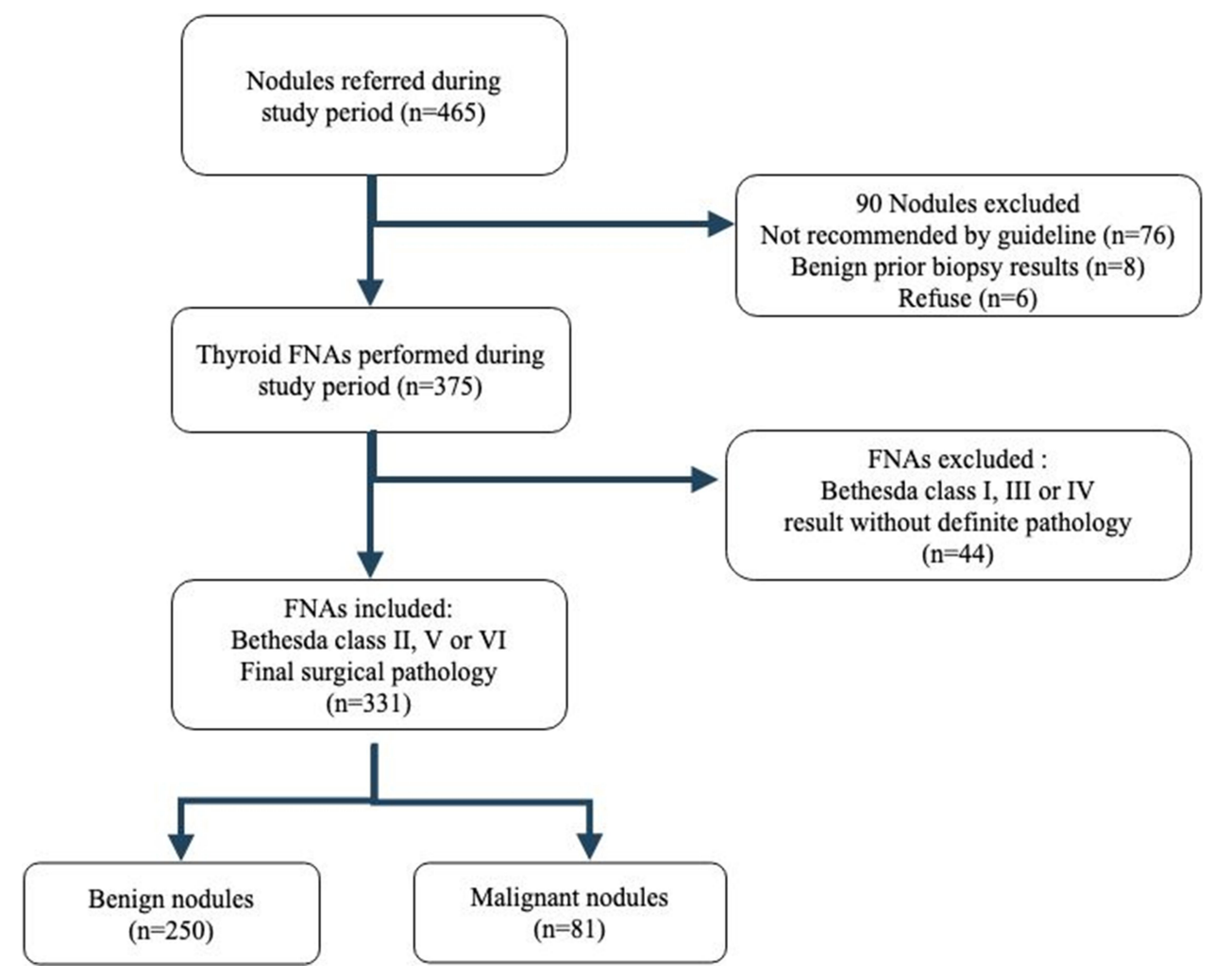

Figure I Flowchart of the study participants. FNA, fine-needle aspiration. 
Table I Malignancy Risk Stratification According to K-TIRADS and FNA Indications

\begin{tabular}{|c|c|c|c|}
\hline Category & US Feature & $\begin{array}{l}\text { Malignancy Risk } \\
\text { (\%) }\end{array}$ & FNA \\
\hline 5. High suspicion & Solid hypoechoic nodule with any of 3 suspicious US features* & $>60$ & $\begin{array}{l}\geq \operatorname{lcm}(>0.5 \mathrm{~cm}, \\
\text { selective })\end{array}$ \\
\hline $\begin{array}{l}\text { 4. Intermediate } \\
\text { suspicion }\end{array}$ & $\begin{array}{l}\text { 1) Solid hypoechoic nodule without any of } 3 \text { suspicious US features* or } \\
\text { 2) Partially cystic or isohyperechoic nodule with any of } 3 \text { suspicious US } \\
\text { features* }\end{array}$ & $15-50$ & $\geq \mathrm{lcm}$ \\
\hline 3. Low suspicion & $\begin{array}{l}\text { Partially cystic or isohyperechoic nodule without any of } 3 \text { suspicious US } \\
\text { features* }\end{array}$ & $3-15$ & $\geq 1.5 \mathrm{~cm}$ \\
\hline 2. Benign & $\begin{array}{l}\text { I) Spongiform } \\
\text { 2) Partially cystic nodule with comet tail artifact } \\
\text { 3) Pure cyst }\end{array}$ & $<3$ & $\geq 2 \mathrm{~cm}$ \\
\hline I. No nodule & & & \\
\hline
\end{tabular}

Notes: K-TIRADS, Korean Thyroid Imaging Reporting and Data System; FNA, fine needle aspiration; US, ultrasonography; *Microcalcification, nonparallel orientation (taller-than-wide), spiculated/microlobulated margin.

Institutional Review Board of Catholic Medical Center (KC19RESI0154). Informed consent was exempted by the review board since the study was a retrospective analysis.

\section{Measurement and Classification of Nodules}

Real-time thyroid US was performed using LOGIQ S6 (GE Medical Systems, Chicago, IL) with a $3.5-11 \mathrm{MHz}$ transducer. Features affecting classification, such as echogenicity, calcification, parallel orientation, and regularity of margin, were documented in the examination report at the time of imaging. The length, width, and depth of each nodule were assessed based on the US findings. Maximal diameter was considered as the criteria for performance of FNA. Each nodule was categorized using the K-TIRADS based on the US features (Table 1).

The KTA guidelines only recommend FNA for K-TIRADS 5 nodules $\geq 10 \mathrm{~mm}$ in size. However, in certain conditions, nodules $>5$ and $<10 \mathrm{~mm}$ are also indicated for FNA. According to the KTA guidelines, K-TIRADS 5 nodules suspected of extrathyroidal invasion, or those with a high risk of invasion of the trachea or recurrent laryngeal nerve are indicated for FNA, even if the size is $<10 \mathrm{~mm} .^{11}$ For the selective indication for FNA for K-TIRADS 5 subcentimeter nodules, we considered the following criteria: nodules suspected of thyroid capsular invasion; nodules located at $<2 \mathrm{~mm}$ distance from adjacent surrounding critical structures, ${ }^{12}$ including the recurrent laryngeal nerve, trachea, or carotid artery; and nodules suspected of lymph node (LN) metastasis (Figure 2). Nodules indicated for FNA based on the KTA recommendation were referred to as KTA-positive and nodules that were not, as KTA-negative.

\section{Statistical Analysis}

Data were expressed as mean \pm standard deviation or percentage unless otherwise stated. The mean age, gender,

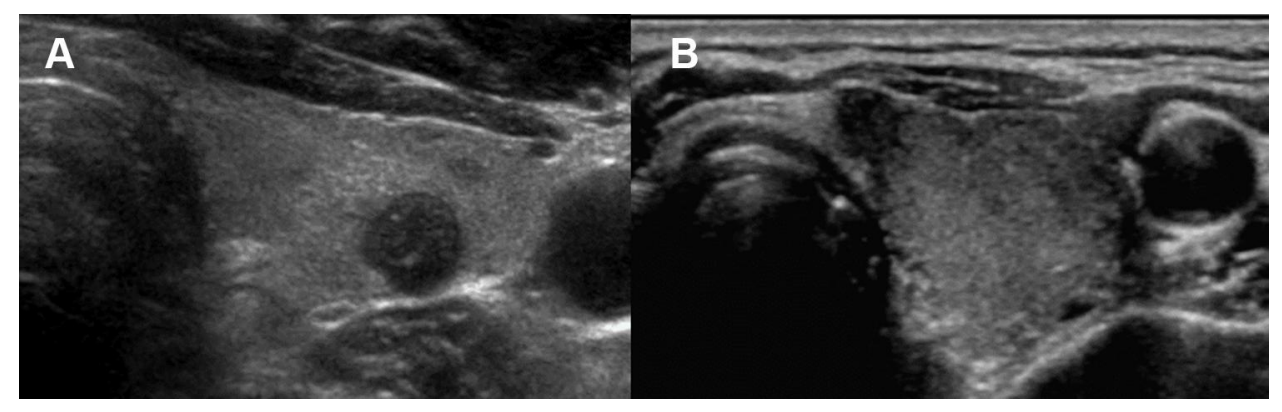

Figure 2 (A) Subcentimeter hypoechoic nodule with speculated margin suspicious of capsular invasion in a 7I-year-old man. (B) Subcentimeter hypoechoic nodule with non-parallel orientation located $<2 \mathrm{~mm}$ from the trachea in a 65 -year-old woman. 
maximal diameter, echogenicity, margin, calcification, and orientation were included as analysis data. The proportion of nodules that met the indications for FNA according to the K-TIRADS was calculated as follows: the number of nodules that satisfied the criteria/total number of nodules $\mathrm{x}$ 100. All statistical analyses were performed using the Statistical Package for the Social Sciences software for Windows Version 24.0 (Armonk, NY: IBM Corp.).

\section{Results}

\section{Baseline Clinical Characteristics of the} Participants and Nodules

The baseline clinical characteristics of the participants and nodules are summarized in Table 2. The mean age of the participants was $53.6 \pm 12.7$ years. Incidental nodules were defined as un unsuspected nodules found in the course of an examination performed for other reasons without any clinical symptoms or suspicion. The mean size of the nodules was $14.8 \pm 9.1 \mathrm{~mm}$, and $123(37.1 \%)$ nodules were $<10 \mathrm{~mm}$ in size. The most common grade of the nodules was K-TIRADS

Table 2 Study Participants $(n=283)$ and Nodules $(n=331)$

\begin{tabular}{|l|l|}
\hline Age (years) & \\
\hline Mean (SD, range) & $53.6(12.7,16-80)$ \\
\hline $\begin{array}{l}\text { Sex, } \mathrm{n}(\%) \\
\text { Male }\end{array}$ & $65(23.0)$ \\
Female & $218(77.0)$ \\
\hline Nodules & \\
Mean size, mm (SD, range) & $14.8(9.1,3-54)$ \\
\hline Nodule size, no. of nodules (\%) & \\
$<$ I0 mm & $123(37.1)$ \\
I0-I4.9 mm & $74(22.3)$ \\
I5-I9.9 mm & $63(19.0)$ \\
$\geq 20$ mm & $71(21.6)$ \\
\hline Nodule discovery (\%) & \\
Incidental & $211(63.7)$ \\
Non-incidental & $24(7.2)$ \\
Unknown & $96(29.1)$ \\
\hline K-TIRADS ${ }^{\text {a }}$ & \\
I & $0(0.0 \%)$ \\
2 & $1(0.0 \%)$ \\
3 & $120(36.5 \%)$ \\
4 & $139(42.0 \%)$ \\
5 &
\end{tabular}

Note: ${ }^{a}$ K-TIRADS, the Korean Thyroid Imaging Reporting and Data System. Abbreviation: SD, standard deviation.
$5(42 \%)$, followed by K-TIRADS $4(36.5 \%)$. As the K-TIRADS grade increased, more FNAs were performed.

\section{Proportion of Nodules Accurately Indicated for FNA According to the KTA Guidelines}

Of the 331 biopsied nodules, 225 (68\%) were KTApositive (Table 3), whereas 106 (32\%) were KTAnegative but FNA had been performed. Of the 123 subcentimeter nodules, 28 were selectively indicated for FNA and were classified as KTA-positive (Table 4). Sixteen nodules were closer than $2 \mathrm{~mm}$ to the trachea or carotid artery, and 11 nodules were found to invade the thyroid capsule. One nodule was suspected of LN metastasis. The rest of the 95 subcentimeter nodules were KTA-negative but had FNA results. When the results were sub analyzed by age, the probability of performance of FNA did not differ (Supplementary Table 1).

Table 3 Proportion of Nodules Accurately Indicated for FNA According to the KTA Guidelines

\begin{tabular}{|l|l|l|l|}
\hline \multirow{2}{*}{ K-TIRADS $^{\mathbf{a}}$} & \multirow{2}{*}{ Total } & \multicolumn{2}{|l|}{ KTA $^{\mathbf{b}}$} \\
\cline { 3 - 4 } & & Positive & Negative \\
\hline 1 & 0 & $0(0.0 \%)$ & $0(100.0 \%)$ \\
2 & 1 & $0(0.0 \%)$ & $1(100.0 \%)$ \\
3 & 71 & $53(74.6 \%)$ & $18(25.4 \%)$ \\
4 & 120 & $84(70.0 \%)$ & $36(30.0 \%)$ \\
5 & 139 & $88(63.3 \%)$ & $51(36.7 \%)$ \\
Total & 331 & $225(68.0 \%)$ & $106(32.0 \%)$ \\
\hline
\end{tabular}

Notes: ${ }^{a}$ K-TIRADS, the Korean Thyroid Imaging Reporting and Data System; an indication for biopsy was adopted according to the guidelines suggested by the

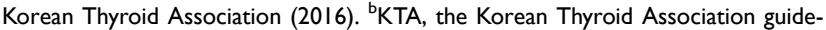
lines for FNA.

Table 4 Proportion of Subcentimeter Nodules Accurately Indicated for FNA According to the KTA Guidelines

\begin{tabular}{|l|l|l|l|}
\hline \multirow{2}{*}{ K-TIRADS $^{\mathbf{a}}$} & \multirow{2}{*}{ Total } & \multicolumn{2}{|l|}{ KTA $^{\mathbf{b}}$} \\
\cline { 3 - 4 } & & Positive & Negative \\
\hline 1 & 0 & $0(0.0 \%)$ & $0(100.0 \%)$ \\
2 & 0 & $0(0.0 \%)$ & $0(100.0 \%)$ \\
3 & 8 & $0(0.0 \%)$ & $8(100.0 \%)$ \\
4 & 36 & $0(0.0 \%)$ & $36(100.0 \%)$ \\
5 & 79 & $28(35.4 \%)$ & $51(64.6 \%)$ \\
Total & 123 & $28(22.8 \%)$ & $95(77.2 .0 \%)$ \\
\hline
\end{tabular}

Notes: ${ }^{a}$ K-TIRADS, the Korean Thyroid Imaging Reporting and Data System; an indication for biopsy was adopted according to the guidelines suggested by the

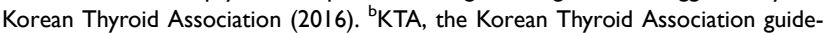
lines for FNA. 
Table 5 Differences in the Proportion of Malignant Nodules According to the KTA Guidelines

\begin{tabular}{|l|l|l|l|l|}
\hline \multirow{2}{*}{ K-TIRADS $^{\mathbf{a}}$} & Total & Malignant Nodules & \multicolumn{2}{|l|}{ KTA $^{\mathbf{b}}$} \\
\cline { 3 - 5 } & & & Positive & Negative \\
\hline 1 & 0 & $0(0.0 \%)$ & $0(0.0 \%)$ & $0(0.0 \%)$ \\
2 & 1 & $0(0.0 \%)$ & $0(0.0 \%)$ & $0(0.0 \%)$ \\
3 & 71 & $4(3.4 \%)$ & $3(2.2 \%)$ & $1(1.2 \%)$ \\
4 & 120 & $11(9.0 \%)$ & $3(2.3 \%)$ & $8(6.7 \%)$ \\
5 & 139 & $66(47.5 \%)$ & $45(32.4 \%)$ & $21(15.1 \%)$ \\
Total & 331 & $81(24.5 \%)$ & $51(15.4 \%)$ & $30(9.1 \%)$ \\
\hline
\end{tabular}

Notes: ${ }^{a}$ K-TIRADS, the Korean Thyroid Imaging Reporting and Data System; an indication for biopsy was adopted according to the guidelines suggested by the Korean Thyroid Association (2016). ' $\mathrm{KTA}$, the Korean Thyroid Association guidelines for FNA.

Table 6 Clinical Outcomes of Malignant Subcentimeter Nodules According to the KTA Guidelines

\begin{tabular}{|l|l|l|l|}
\hline Management & Malignant Nodules & KTA & Negative \\
\cline { 2 - 4 } & & Positive & $18(36.7 \%)$ \\
\hline Surgical resection & $33(67.3 \%)$ & $15(30.6 \%)$ & $6(12.2 \%)$ \\
Total thyroidectomy & & $6(12.2 \%)$ & $10(20.4 \%)$ \\
Lobectomy & & $9(18.4 \%)$ & $2(4.1 \%)$ \\
Isthmusectomy & & $0(0.0 \%)$ & $11(22.5 \%)$ \\
Follow up loss & $14(28.6 \%)$ & $3(6.1 \%)$ & $2(4.1 \%)$ \\
Active surveillance & $2(4.1 \%)$ & $0(0.0 \%)$ & $31(63.3 \%)$ \\
Total & $49(100 \%)$ & $18(36.7 \%)$ & \\
\hline
\end{tabular}

Note: ${ }^{a}$ KTA, the Korean Thyroid Association guidelines for FNA.

\section{Differences in the Proportion of Malignant Nodules According to the KTA Guidelines}

Of the 331 nodules, 81 (24.5\%) were malignant (Table 5). Of 123 (37.1\%) subcentimeter nodules, 49 (14.8\%) were malignant. That is, there were $18(5.4 \%)$ and $31(9.4 \%)$ malignant subcentimeter KTA-positive and KTA-negative nodules, respectively.

\section{Clinical Outcomes of Malignant Subcentimeter Nodules According to the KTA Guidelines}

Of the 49 malignant subcentimeter nodules, 33 (67.6\%) underwent surgical resection, and 14 (28.6\%) were lost to follow-up, as they might have sought second opinions or visited a different hospital for surgery. Among the 33 nodules resected, 15 (30.6\%) were KTA-positive and 18 (36.7\%) KTA-negative (Table 6). LN metastasis was found in $9(18.4 \%)$ KTA-positive nodules and in $9(18.4 \%)$ KTAnegative nodules via a postsurgical pathological review. In other words, there were 9 (18.4\%) malignant subcentimeter nodules without capsular invasion and pathological
$\mathrm{LN}$ metastasis which were located at a $2 \mathrm{~mm}$ distance from important surrounding structures. However, these nodules were surgically resected.

\section{Discussion}

A large percentage (32\%) of thyroid nodules are aspirated in real-world practice, even if they do not meet the indication for FNA. Previous studies, such those of Ahn et al and Hobbs et al, have shown that $40 \%$ and $24 \%$ of nodules that underwent FNA did not meet the recommendations for FNA, respectively. ${ }^{13,14}$ The increase in the number of unnecessary FNAs can be attributed to the risk averse trends of physicians due to the fear of missing the detection of a malignancy. ${ }^{15}$ In addition, considering that the patients referred to a tertiary hospital in Korea would return to their primary physicians for follow-up, tertiary center physicians must have found it difficult to ignore the requests of the primary physicians for FNA.

Our data showed that numerous nodules $<10 \mathrm{~mm}$ in size underwent biopsy. In most clinical guidelines, biopsy is not routinely recommended for nodules $<10 \mathrm{~mm}$ because it is unclear whether an aggressive biopsy is beneficial in a small-sized asymptomatic thyroid 
nodule. ${ }^{16,17}$ Several studies have shown that the immediate biopsy of small nodules leading to definitive therapy until disease progression has no impact on disease-specific survival; ${ }^{12,18-21}$ rather, active surveillance without biopsy can be conducted. ${ }^{22,23}$

However, the decision as to whether the nodule should undergo either biopsy or surveillance without biopsy varies according to different guidelines and has been an emerging issue in the case of subcentimeter nodules. ${ }^{24}$ According to the European Thyroid Association guidelines, all subcentimeter nodules with no clinically definite abnormal LN can undergo surveillance without biopsy. ${ }^{25}$ The American College of Radiology guidelines and the American Thyroid Association guidelines (ATA) only recommend FNA for subcentimeter nodules in patients with conditions such as LN metastasis, distant metastasis, and extrathyroidal extension. ${ }^{26,27}$ By contrast, the KTA guidelines (K-TIRADS) ${ }^{11}$ and the Japan Association of Breast \& Thyroid Sonology guidelines ${ }^{28}$ have a lower threshold for biopsy and recommend selective FNA for nodules $>5$ and $<10 \mathrm{~mm}$ in the presence or suspicion of extrathyroidal extensions, cervical LN or distant metastasis, tracheal or recurrent laryngeal nerve invasion, and tumor progression, that is, in the presence of conditions that can later complicate surgery. ${ }^{11}$

In our study that was based on the KTA guidelines for selecting subcentimeter nodules, the cut-off distance for surrounding invasion was $2 \mathrm{~mm}$ because it is considered to be the degree of error in US measurement that is within the range of observer variation. ${ }^{12,18}$ Numerous subcentimeter nodules which do not meet the indication are aspirated in real-world practice. Several guidelines only recommend highly suspicious subcentimeter nodules for biopsy; however, it has been observed that these guidelines are not being followed the real field practice. The current guidelines have limited guidance on how to specifically contextualize the biopsy decision using important patient factors such as age or comorbidity status or patient preference. $^{29}$

In terms of malignancy, the proportion of malignant subcentimeter nodules accounted for more than half of the total malignant nodules, which indicates that overdiagnosis of malignant subcentimeter nodules might have led to the increased incidence of thyroid malignancy.,30 In general, malignant subcentimeter nodules have low disease-specific mortality, ${ }^{31}$ and the ATA and KTA guidelines recommend active surveillance, instead of surgery, as a reasonable option for papillary microcarcinoma. ${ }^{11,27}$ However, based on real-wor ld data, only a very small number of malignant subcentimeter nodules underwent active surveillance instead of surgery after FNA. After excluding subcentimeter nodules adjacent to important surrounding structures and capsular invasion, which can later complicate surgery. ${ }^{12,32,33} 36.7 \%$ of malignant subcentimeter nodules chose surgery instead of active surveillance. In addition, even after excluding patients who had LN metastasis based on a pathological review, we found that surgery was still performed on $18.4 \%$ of malignant subcentimeter nodules. Aggressive surgery does not only cause a high rate of surgical complications, such as vocal cord paralysis and hypoparathyroidism along with a decreased quality of life, but also increases the economic burden. ${ }^{34}$ Notably, based on realworld data, the overdiagnosis of malignant subcentimeter nodules leads to considerable numbers of surgeries. Surveillance without biopsy could be conducted; therefore, preventing unnecessary FNA is important.

Our study had several limitations. First, this retrospective study was conducted at a single tertiary center in Korea for over 16 months. Our results might not be generalizable to patients in other hospitals or clinics. Second, the US features were described by several radiologists; thus, the heterogenous professional profiles and experience levels of individual physicians who performed thyroid US might have caused interobserver variability. ${ }^{35}$ Furthermore, as the K-TIRAD classification system does not propose a quantitative evaluation of echogenicity, isoechoic nodules might have been misdiagnosed and overgraded to hypoechoic nodules (K-TIRADS 4 or 5), leading to unnecessary FNAs. ${ }^{36}$ Third, the revised KTA guidelines were published on November 30, 2016 and our data collection started from January 1, 2017. There is a possibility that the early data of our study are based on the previous KTA guidelines that were revised in 2010. Lastly, this study is applicable only to Korean institutions. KTA 2016 guidelines have a lower biopsy threshold than ATA 2015 guidelines with regard to subcentimeter nodules. This difference in risk stratification is to be considered.

\section{Conclusions}

This is one of the few studies that presents real-world data related to performance of FNA in thyroid nodules. The perception gap between the guidelines in the literature and real-world practice was rather huge. Although not indicated, biopsy is frequently performed particularly for subcentimeter nodules in actual clinical settings. Overdiagnosis not only affects a patient's quality of life but also leads to overtreatment, as previously discussed. 
To reduce health care costs and overtreatment, widespread knowledge of the correct indications for biopsy according to established guidelines is important in clinical practice.

\section{Acknowledgment}

The abstract of this manuscript has been presented as a poster in the $89^{\text {th }}$ annual meeting of the American Thyroid Association in 2019 in Chicago.

\section{Author Contributions}

All authors made a significant contribution to the work reported, whether that is in the conception, study design, execution, acquisition of data, analysis and interpretation, or in all these areas; took part in drafting, revising or critically reviewing the article; gave final approval of the version to be published; have agreed on the journal to which the article has been submitted; and agree to be accountable for all aspects of the work.

\section{Funding}

This research did not receive any specific grant from any funding agency in the public, commercial, or not-for-profit sector.

\section{Disclosure}

The authors declare no conflicts of interest.

\section{References}

1. Aschebrook-Kilfoy B, Schechter RB, Shih YC, et al. The clinical and economic burden of a sustained increase in thyroid cancer incidence. Cancer Epidemiol Biomarkers Prev. 2013;22(7):1252-1259. doi:10.1158/1055-9965.EPI-13-0242

2. Burgess JR, Tucker P. Incidence trends for papillary thyroid carcinoma and their correlation with thyroid surgery and thyroid fine-needle aspirate cytology. Thyroid. 2006;16(1):47-53. doi:10.1089/ thy.2006.16.47

3. Leenhardt L, Grosclaude P, Chérié-Challine L; Thyroid Cancer Committee. Increased incidence of thyroid carcinoma in france: a true epidemic or thyroid nodule management effects? Report from the French Thyroid Cancer Committee. Thyroid. 2004;14 (12):1056-1060. doi:10.1089/thy.2004.14.1056

4. Davies L, Welch HG. Increasing incidence of thyroid cancer in the United States, 1973-2002. JAMA. 2006;295(18):2164-2167. doi:10.1001/jama.295.18.2164

5. Ahn HS, Welch HG. South Korea's thyroid-cancer "epidemic" - turning the tide. $N$ Engl J Med. 2015;373(24):2389-2390. doi:10.1056/ NEJMc1507622

6. Coorough N, Hudak K, Buehler D, Selvaggi S, Sippel R, Chen H. Fine needle aspiration of the thyroid: a contemporary experience of 3981 cases. J Surg Res. 2011;170(1):48-51. doi:10.1016/j.jss.2011.02.048

7. Kwak JY, Han KH, Yoon JH, et al. Thyroid imaging reporting and data system for US features of nodules: a step in establishing better stratification of cancer risk. Radiology. 2011;260(3):892-899. doi:10.1148/ radiol.11110206
8. Yi KH, Lee EK, Kang H-C, et al. 2016 Revised Korean Thyroid Association Management guidelines for patients with thyroid nodules and thyroid cancer. Int J Thyroidol. 2016;9:59-126.

9. Kiernan CM, Solorzano CC. Bethesda category iii, iv, and v thyroid nodules: can nodule size help predict malignancy? J Am Coll Surg. 2017;225(1):77-82. doi:10.1016/j.jamcollsurg.2017.02.002

10. Cibas ES, Ali SZ. The 2017 Bethesda system for reporting thyroid cytopathology. Thyroid. 2017;27(11):1341-1346. doi:10.1089/ thy.2017.0500

11. Yi KH, Revised T. 2016 Korean Thyroid Association guidelines for thyroid nodules and cancers: differences from the 2015 American Thyroid Association Guidelines. Endocrinol Metab. 2016;31 (3):373-378. doi:10.3803/EnM.2016.31.3.373

12. Brito JP, Ito Y, Miyauchi A, Tuttle RM. A clinical framework to facilitate risk stratification when considering an active surveillance alternative to immediate biopsy and surgery in papillary microcarcinoma. Thyroid. 2016;26(1):144-149. doi:10.1089/ thy. 2015.0178

13. Hobbs HA, Bahl M, Nelson RC, Eastwood JD, Esclamado RM, Hoang JK. Applying the Society of Radiologists in Ultrasound recommendations for fine-needle aspiration of thyroid nodules: effect on workup and malignancy detection. AJR Am J Roentgenol. 2014;202(3):602-607. doi:10.2214/AJR.13.11219

14. Ahn SS, Kim EK, Kang DR, Lim SK, Kwak JY, Kim MJ. Biopsy of thyroid nodules: comparison of three sets of guidelines. AJR Am J Roentgenol. 2010;194(1):31-37. doi:10.2214/AJR.09.2822

15. Ha SM, Baek JH, Choi YJ, et al. Malignancy risk of initially benign thyroid nodules: validation with various Thyroid Imaging Reporting and Data System guidelines. Eur Radiol. 2019;29(1):133-140. doi:10.1007/s00330-018-5566-0

16. Ha EJ, Na DG, Baek JH, Sung JY, Kim JH, Kang SY. US fine-needle aspiration biopsy for thyroid malignancy: diagnostic performance of Seven Society guidelines applied to 2000 thyroid nodules. Radiology. 2018;287(3):893-900. doi:10.1148/radiol.2018171074

17. Brito JP, Morris JC, Montori VM. Thyroid cancer: zealous imaging has increased detection and treatment of low risk tumours. BMJ. 2013;347(aug27 4):f4706. doi:10.1136/bmj.f4706

18. Haser GC, Tuttle RM, Su HK, et al. Active surveillance for papillary thyroid microcarcinoma: new challenges and opportunities for the health care system. Endocr Pract. 2016;22(5):602-611. doi:10.4158/ EP151065.RA

19. Cho SJ, Suh CH, Baek JH, et al. Active surveillance for small papillary thyroid cancer: a systematic review and meta-analysis. Thyroid. 2019;29(10):1399-1408. doi:10.1089/thy.2019.0159

20. Sakai T, Sugitani I, Ebina A, et al. Active surveillance for T1bN0M0 papillary thyroid carcinoma. Thyroid. 2019;29(1):59-63. doi:10.1089/thy.2018.0462

21. Oh HS, Ha J, Kim HI, et al. Active surveillance of low-risk papillary thyroid microcarcinoma: a multi-center cohort study in Korea. Thyroid. 2018;28(12):1587-1594. doi:10.1089/thy.2018.0263

22. Sugitani I, Toda K, Yamada K, Yamamoto N, Ikenaga M, Fujimoto Y. Three distinctly different kinds of papillary thyroid microcarcinoma should be recognized: our treatment strategies and outcomes. World J Surg. 2010;34(6):1222-1231. doi:10.1007/ s00268-009-0359-x

23. Ito $\mathrm{Y}$, Miyauchi A, Inoue $\mathrm{H}$, et al. An observational trial for papillary thyroid microcarcinoma in Japanese patients. World J Surg. 2010;34 (1):28-35. doi:10.1007/s00268-009-0303-0

24. Kovatch KJ, Hoban CW, Shuman AG. Thyroid cancer surgery guidelines in an era of de-escalation. Eur J Surg Oncol. 2018;44 (3):297-306. doi:10.1016/j.ejso.2017.03.005

25. Russ G, Bonnema SJ, Erdogan MF, Durante C, Ngu R, Leenhardt L. European Thyroid Association guidelines for ultrasound malignancy risk stratification of thyroid nodules in adults: the EU-TIRADS. Eur Thyroid J. 2017;6(5):225-237. doi:10.1159/000478927 
26. Tessler FN, Middleton WD, Grant EG, et al. ACR Thyroid Imaging, Reporting and Data System (TI-RADS): white paper of the ACR TI-RADS Committee. J Am Coll Radiol. 2017;14(5):587-595. doi:10.1016/j.jacr.2017.01.046

27. Haugen BR, Alexander EK, Bible KC, et al. 2015 American Thyroid Association Management guidelines for adult patients with thyroid nodules and differentiated thyroid cancer: the American Thyroid Association guidelines task force on thyroid nodules and differentiated thyroid cancer. Thyroid. 2016;26(1):1-133. doi:10.1089/ thy. 2015.0020

28. Masafumi K, Shinichi S; Japan Association of Breast and Thyroid Sonology. Thyroid Ultrasound - A Guidebook for Diagnosis and Management. 3rd ed. Nankodo: Tokyo, Japan; 2016.

29. Genere N, Hurtado MD, Cortes T, et al. Drivers of the decision to biopsy and follow-up of small suspicious thyroid nodules. Endocr Pract. 2020. doi:10.4158/EP-2019-0590

30. Grodski S, Brown T, Sidhu S, et al. Increasing incidence of thyroid cancer is due to increased pathologic detection. Surgery. 2008;144 (6):1038-1043. doi:10.1016/j.surg.2008.08.023

31. Mazzaferri EL. Management of low-risk differentiated thyroid cancer. Endocr Pract. 2007;13(5):498-512. doi:10.4158/EP.13.5.498
32. Leboulleux S, Tuttle RM, Pacini F, Schlumberger M. Papillary thyroid microcarcinoma: time to shift from surgery to active surveillance? Lancet Diabetes Endocrinol. 2016;4(11):933-942. doi:10.1016/ S2213-8587(16)30180-2

33. Brito JP, Hay ID, Morris JC. Low risk papillary thyroid cancer. $B M J$. 2014;348(jun16 9):g3045. doi:10.1136/bmj.g3045

34. Rosato L, Avenia N, Bernante P, et al. Complications of thyroid surgery: analysis of a multicentric study on 14,934 patients operated on in italy over 5 years. World J Surg. 2004;28(3):271-276. doi:10.1007/s00268-003-6903-1

35. Su HK, Dos Reis LL, Lupo MA, et al. Striving toward standardization of reporting of ultrasound features of thyroid nodules and lymph nodes: a multidisciplinary consensus statement. Thyroid. 2014;24 (9):1341-1349. doi:10.1089/thy.2014.0110

36. Na DG, Baek JH, Sung JY, et al. Thyroid imaging reporting and data system risk stratification of thyroid nodules: categorization based on solidity and echogenicity. Thyroid. 2016;26(4):562-572. doi:10.1089/ thy. 2015.0460

\section{Publish your work in this journal}

Cancer Management and Research is an international, peer-reviewed open access journal focusing on cancer research and the optimal use of preventative and integrated treatment interventions to achieve improved outcomes, enhanced survival and quality of life for the cancer patient.
The manuscript management system is completely online and includes a very quick and fair peer-review system, which is all easy to use. Visit http://www.dovepress.com/testimonials.php to read real quotes from published authors. 